\title{
FEATURE \\ Combining precision conservation technologies into a flexible framework to facilitate agricultural watershed planning
}

doi:10.2489/jswc.68.5.113A

Mark D. Tomer, Sarah A. Porter, David E. James, Kathleen M.B. Boomer, Jill A. Kostel, and

Eileen McLellan

$\mathrm{T}$ he need to reduce nutrient loads from agricultural watersheds poses a daunting challenge, considering the continental scale of water quality problems in the Gulf of Mexico (Turner et al. 2008), Great Lakes (Joose and Baker 2010), and Chesapeake Bay (Russell et al. 2008). Strategies to address nutrient reduction have suggested that a mix of practices will be required across multiple landscape positions to achieve water quality goals (Iowa Nutrient Reduction Strategy Science Team 2012). Control of both nitrogen and phosphorus may be critical to mitigate eutrophication of freshwaters, estuaries, and marine shelves (Paerl 2009), further emphasizing the need for comprehensive approaches to control agricultural nutrient losses. However, water quality must be improved while agricultural production is becoming more intensified (Lobell et al. 2009). Practices that sustain soil health offer the clearest opportunity to maintain crop production, water supply, and other ecosystem services derived from our agricultural landscapes (Kibblewhite et al. 2008). Our premise is that precision conservation technologies, which can help manage agricultural soils within fields (Delgado and Berry 2008) and place conservation practices below fields (Tomer et al. 2003), could provide the basis for developing watershed-specific strategies to improve environmental conditions and agricultural production with efficiency and flexibility, if these technologies could be developed into readily accessible tools. We suggest that conservation planning in watersheds should reinforce the importance of soil management and soil

Mark D. Tomer is research soil scientist, Sarah A. Porter is physical science technician, and David E. James is geographic information specialist at the National Laboratory for Agriculture and the Environment, USDA Agricultural Research Service, Ames, lowa. Kathleen M.B. Boomer is watershed scientist at The Nature Conservancy, Washington, DC. Jill A. Kostel is environmental engineer at the Wetlands Initiative, Chicago, Illinois. Eileen McLellan is scientist at the Environmental Defense Fund, Washington, DC. health to improve nutrient- and wateruse efficiencies in fields, and then, without prescriptive aim, apply geographic analyses to identify a suite of possibilities for conservation practices to control/reduce water and nutrient movement within fields, at and below field edges, and in riparian zones (figure 1).

Conservationists and farm producers recognize that conservation practices should be located where they can be most effective (Arbuckle 2012). Precision conservation technology simply needs to be applied in a way that respects the cultural values of our agricultural communities. This article proposes a framework that can be informed by landowner and community preferences, is compatible with voluntary implementation policies, and could be used to achieve the potential broadbased benefits of precision conservation in a flexible way. The framework is not prescriptive, but identifies many options to precisely locate multiple practices to provide conservation planning scenarios that can be evaluated at watershed and farm levels. Application of this framework provides a planning resource to help watershed communities explore options to expand ecosystem services (including crop production) obtained from agricultural landscapes. The approach holds to the idea that individual voluntary conservation can better enable natural resources to serve wider society if these voluntary efforts are informed by precision conservation technologies. The framework is based on practices known to improve soil and water quality in the Midwest and can be adopted to include new practices that might also effectively address water quality in unique settings.

\section{OVERVIEW OF FRAMEWORK}

The framework (figure 2) first reinforces soil health as being critical to improve nutrient- and water-use efficiencies and then distinguishes areas dominated by

\section{Figure 1}

Conservation practices in a watershed, conceptualized as a pyramid. Healthy agricultural soils will improve the effectiveness of practices placed within fields, below fields, and in riparian zones.

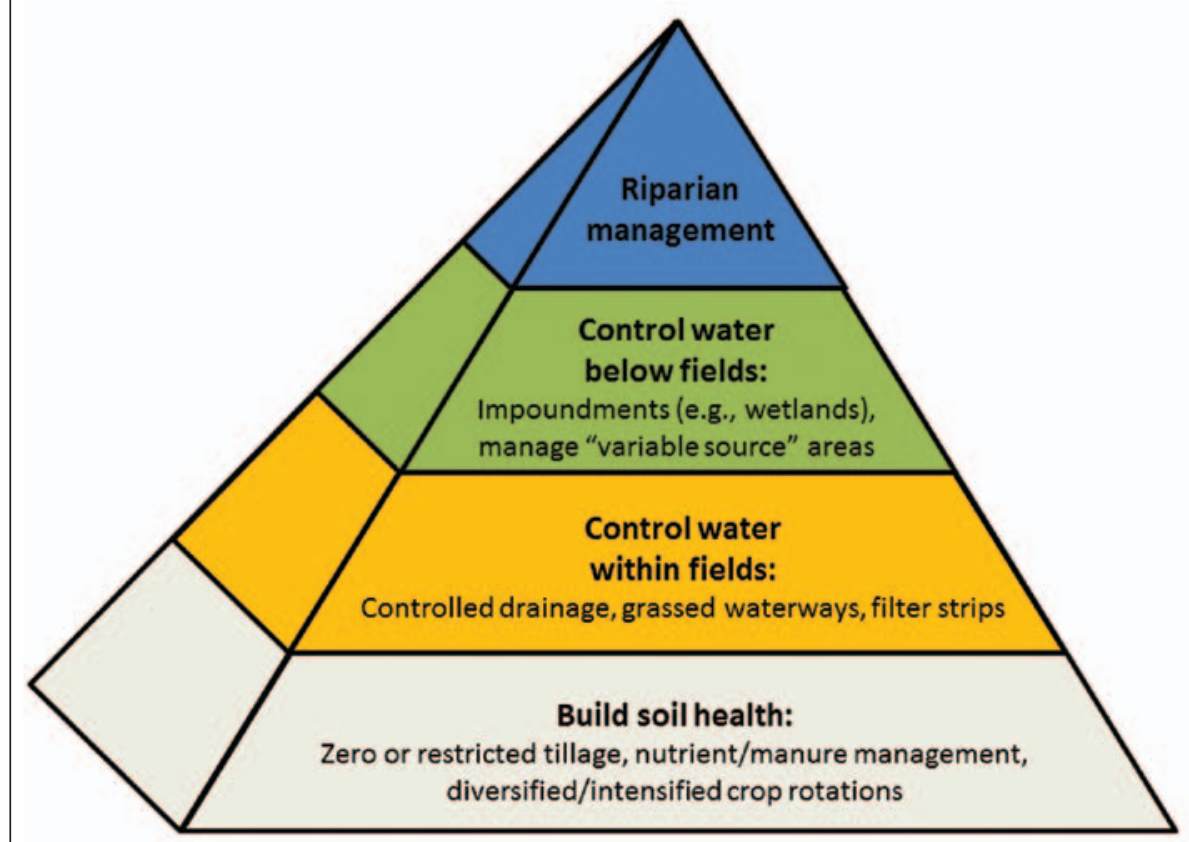




\section{Figure 2}

A framework for watershed-scale conservation planning using precision technologies.

\section{Process for conservation planning to improve water quality in agricultural watersheds using precision technologies} DATA REQUIRED: LIDAR-based digitale levation mode, Soil survey, Field boundaries, Land use

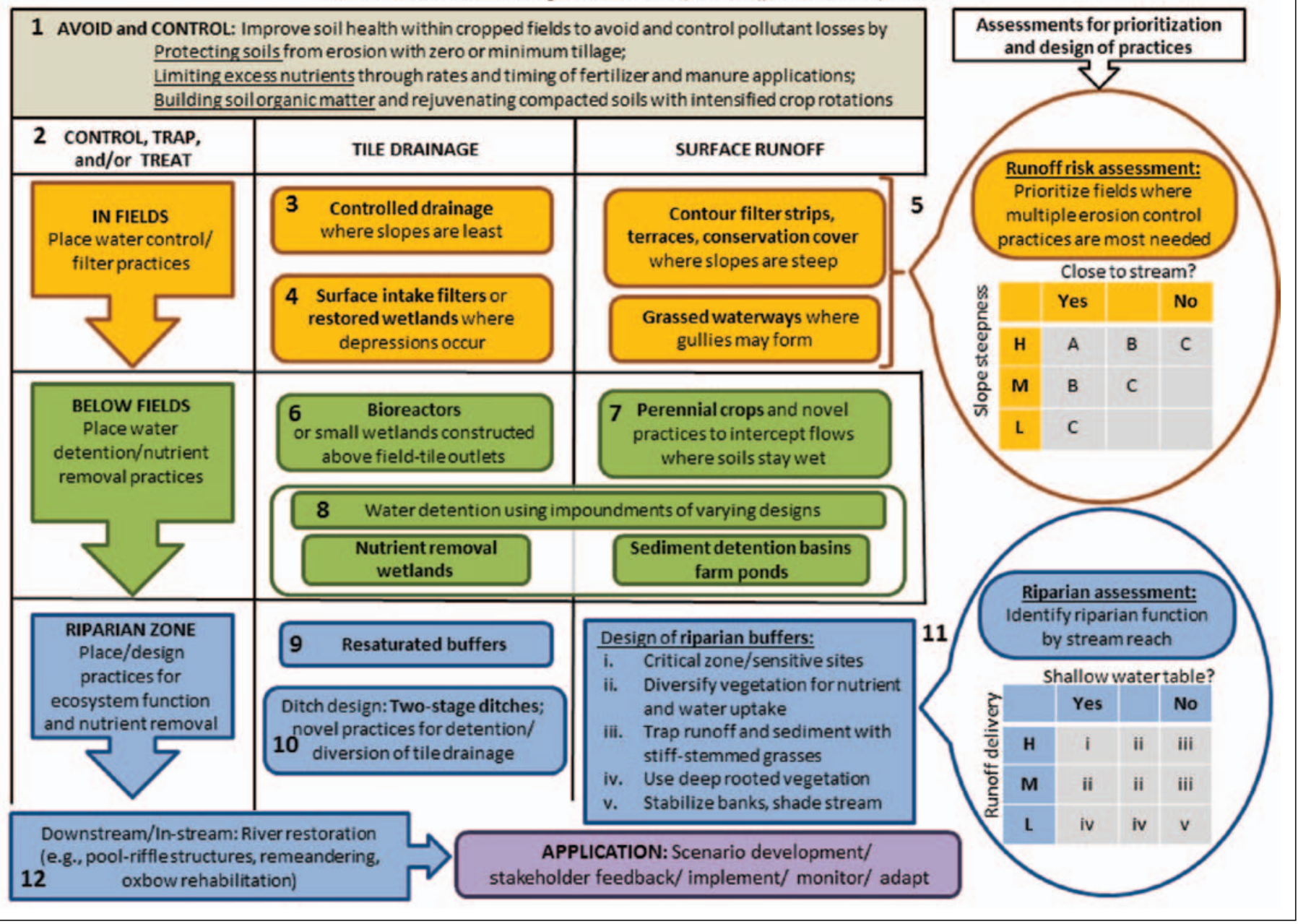

artificial (i.e., subsurface tile) drainage and by surface runoff. The Midwest has extensive areas of poorly drained soils that require tile drainage to be farmed successfully, but nutrient transport through tiles poses a key water quality concern (Kalita et al. 2006). After delineating tile drained areas, candidate sites to implement specific practices are mapped within fields at and below field edges and along riparian zones for tile- and surface-drained areas. Accordingly, three scales (in-field, below field, and riparian) and two pathways (tile drainage and surface runoff) form a 3 by 2 matrix that is the framework's dominant feature. Application of the framework comprises twelve steps (figure 2).

The framework has two supplemental matrices (figure 2, right side). The first, at Step 5, prioritizes fields in which run- off-control practices should most benefit surface water quality. The second, at Step 11, highlights how riparian buffers can be designed using types and widths of vegetation to match the opportunities landscapes naturally provide along riparian corridors. These matrices do not restrict the planning process. Erosion control practices have multiple benefits, and Step 5 emphasizes control of runoff from steep slopes near streams; the landowner decides which practice(s) to apply. In addition, multiple benefits are realized from placing buffers throughout riparian corridors; Step 11 does not restrict buffer installations to particular stream reaches, but it distinguishes opportunities for riparian zone management found throughout a watershed.

River restoration practices complete the framework at Step 12. Results from all steps are then combined, providing many options based on precision technologies that planners and stakeholders can use to develop and consider conservation planning scenarios. Because hypothetical distributions can be mapped/proposed for many practices among all fields in a watershed, individual fields and farms are not targeted for implementation, and results can suggest options and scenarios for evaluation based on expected environmental performance and on landowner preferences. The framework would typically be applied in a Hydrologic Unit Code (HUC) 12 watershed, which is usually 15,000 to 35,000 ac $(6,000$ to $14,000 \mathrm{ha})$ in size. Field-scale information is critical to the process because many conservation practices are implemented in fields or at field edges. The framework therefore relies 
on the availability of input data that can help propose placement schemes for conservation practices that are implemented in fields. Application of the framework should provide information that allows any landowner to identify and select options to improve resource management on his/her farm and watershed.

The framework is also flexible because after Step 2, all steps are independent and optional. Including at least one in-field, one below-field, and one riparian zone, practice would provide a minimal application of the framework. As practices are added, more alternatives can be identified, which adds flexibility in planning for landowners and other stakeholders.

Step One. Before illustrating this framework using an example watershed, we begin with general comments on soil-building practices. Specific ongoing crop and soil management practices in a watershed are beyond our scope here, but obviously must be carefully considered in watershed planning. Eliminating or restricting tillage to minimize soil erosion (Montgomery 2007) and managing to minimize nutrient losses are fundamental to managing agricultural watersheds. Soil health may be impaired by legacies of past soil erosion, compaction, organic matter loss, etc., but this damage is not necessarily permanent (Yaalon 2007). Rotational practices, including cover crops, green manures, and perennial forages, can address these legacy impacts and improve production without increasing fertilizer use (Mueller et al. 2012). Soil-building practices in fields will allow conservation practices below fields and in riparian zones to be more effective and easily maintained (figure 1). While emphasizing soil-health practices near streams and on sensitive soils befits watershed management goals, the eventual aim should be to build the health of all agricultural soils.

Input Data. The framework process, for steps two through twelve, requires input data (figure 3) that include a detailed digital elevation model (DEM). The DEM used here was a $3 \mathrm{~m}(10 \mathrm{ft})$ raster, interpolated to $1 \mathrm{~cm}$ ( $0.4 \mathrm{in})$ elevation from light detection and ranging (LiDAR) data. The elevation model was preprocessed to allow application of terrain analysis soft-

\section{Figure 3}

Representation of input data for Lime Creek, including terrain, field, and soil information.

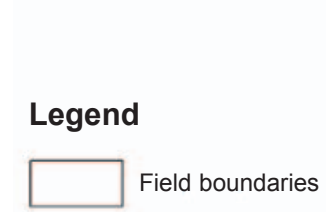

\section{SSURGO soils data}

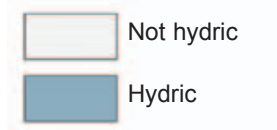

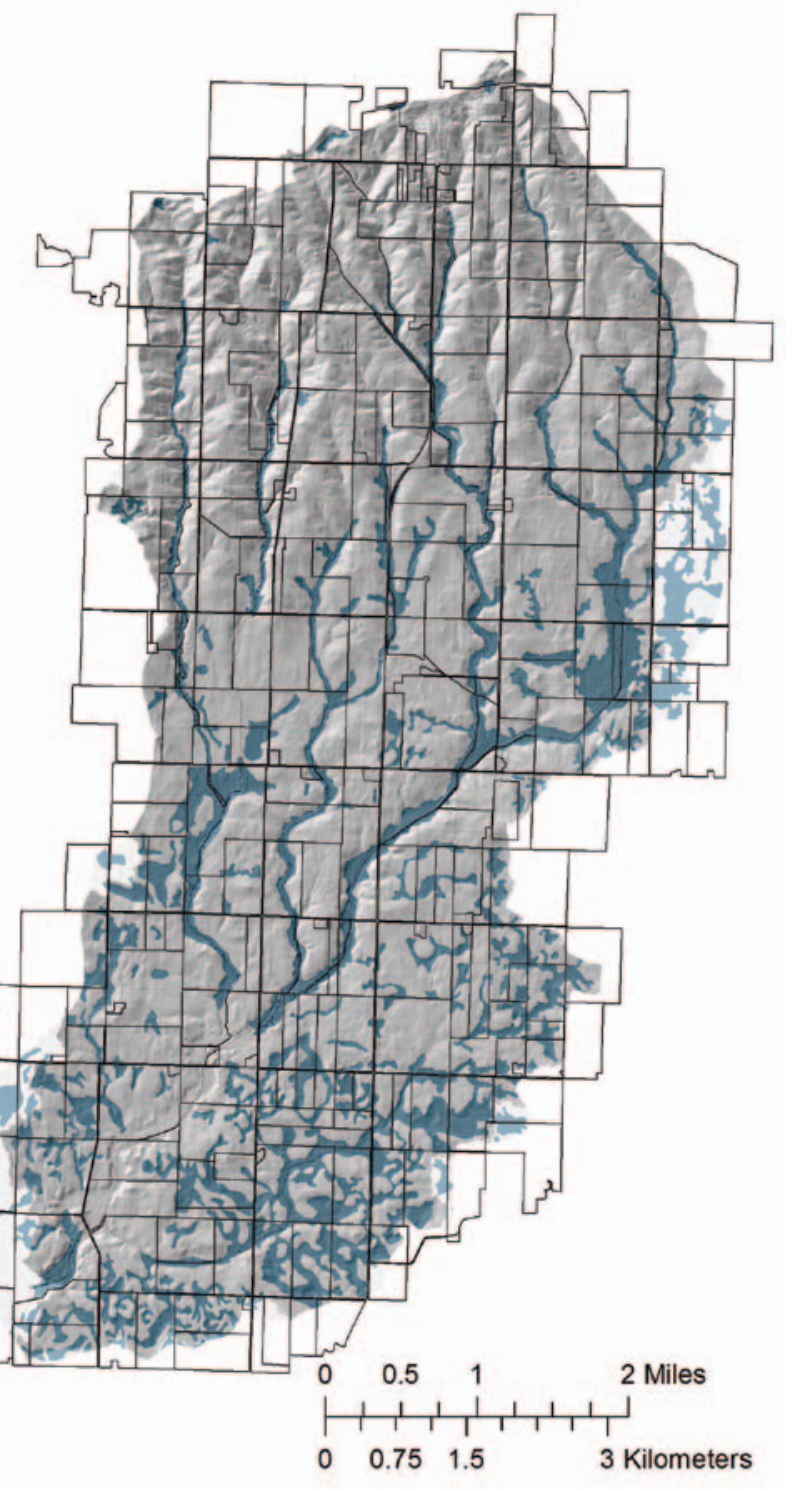

ware (Wilson and Gallant 2000). This required removal of false impoundments to accurately represent flow through bridges and culverts (Tomer et al. 2013). Soil survey information (Soil Survey Staff 2004), agricultural field boundaries, and land cover/rotations on a field basis were also obtained (figure 3). To delineate fields and land cover, a database for Illinois, Iowa, and southern Minnesota was developed beginning with field boundaries publicly released by USDA in 2005, with all farm-level and county-level attribution removed. Boundaries were edited using 2009 National Agricultural Imagery Program (FSA 2012) to minimize the polygons with mixed crop cover. Fields were assigned a crop cover each year for 2007 through 2011 (NASS 2012), and each five-year crop sequence was classified to represent major rotations, including corn and soybean rotations, rotations with other crops, and perennial cover.

\section{EXAMPLE APPLICATION}

Lime Creek in Illinois provides a demonstration of the framework from Step 2. This watershed includes sloping croplands where erosion control would be emphasized for conservation and near-level fields where drainage management would be important. Lime Creek has a simple land- 


\section{Figure 4}

Example output from different steps in the framework.

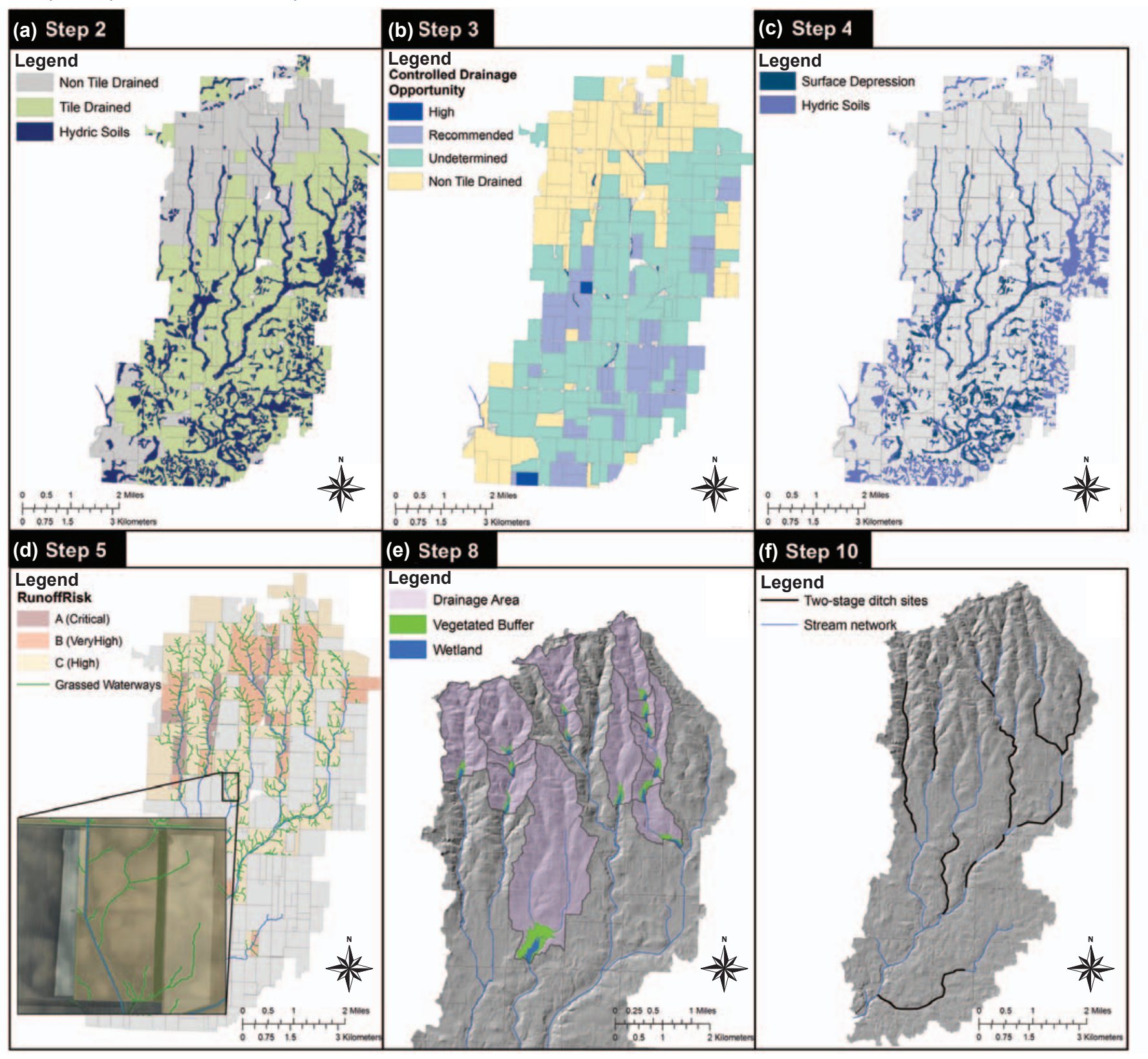

scape, with a glacial moraine grading to a near-level glacial-fluvial plain from north to south (Tomer et al. 2013). Lime Creek is not implied to have conservation needs greater than other watersheds.

Step 2 distinguishes dominant hydrologic pathways of tile drainage and surface runoff. A variety of conservation practices have been designed to control and treat tile drainage, while other conservation practices are designed to control nutrient and sediment losses associated with surface runoff. Therefore, fields that are dominantly tile drained and those where surface runoff is the dominant hydrologic pathway should be distinguished for watershed planning. Maps identifying exact distributions of tile-drained fields are seldom available, but soil condition and slope data can sufficiently delineate tile drainage for planning purposes. Tile drainage underlies essentially any hydric soils found within cropped Midwest fields. Figure $4 \mathrm{a}$ shows fields with $>10 \%$ hydric soils and/or at least $90 \%$ of the field with
$<5 \%$ slope to represent the extent of tile drainage in this watershed.

Step 3 assesses the potential to manage tile drainage water within fields using controlled drainage (i.e., water table management), which can decrease nitrate losses and improve yields (Woli et al. 2010). This practice is easiest to install in flat fields (i.e., $<1 \%$ slope). Figure $4 \mathrm{~b}$ shows fields with $>90 \%$ extent of $<1 \%$ slopes as a "high" opportunity for controlled drainage, while fields that have $80 \%$ to $90 \%$ extent of $<1 \%$ slopes are "recommended" for evalua- 
tion. Controlled drainage may be possible in other areas, but more control gates are needed as topographic variation increases.

Step 4 addresses surface depressions (prairie potholes) that occur in many glacial landscapes. These depressions pond surface water and have surface-water inlets installed to reduce crop inundation. Surface inlets can increase phosphorus and sediment contributions to surface waters (Smith et al. 2008). Depressions can be accurately located using a LiDARderived DEM. Figure $4 \mathrm{c}$ depicts where depressions and hydric soils coincide in Lime Creek, where conservation practices such as wetlands, vegetated inlet buffers, or other filters (e.g., "blind inlets") could be considered.

Step 5 identifies sloping fields near streams where restricted tillage and runoffcontrol practices (i.e., grassed waterways, contour filter strips) may be recommended in combination. In Lime Creek, all fields were ranked by slope steepness in descending order and by runoff-pathway distance to the stream in ascending order. Each field was classed into the upper 20 percentile, 20 to 60 percentiles, or 60 to 100 percentiles for both rankings (table 1 ). These classifications consider Lime Creek only, but could be changed to specific slope or distance-to-stream values to compare with other watersheds or to apply a phosphorus index. In figure $4 d$, "critical" fields for runoff control are in the top 20\% for both rankings. Fields in the upper 20\% of one ranking and next $40 \%$ of the other are "very high", etc., based on table 1 . One conservation practice to control runoff in fields is the grassed waterway. Figure $4 d$ suggests locations for grassed waterways in fields highlighted by this cross-classification. Several precision techniques are available to place grassed waterways (Pike et al. 2009). Precision techniques could be used to propose placement of other practices (figure 2) for any given field.

Step 6 considers placement of bioreactors, which pass diverted tile flow through a carbon-rich substrate to encourage denitrification (Schipper et al. 2010; Woli et al. 2010). Bioreactors are installed below fields adjacent to drainage ditches or tile mains, where local relief allows water to pass through the bioreactor under grav-

\section{Table 1}

Classification scheme to assess runoff risk among fields in Lime Creek (see figure 4d).

\begin{tabular}{llll}
\hline & \multicolumn{2}{l}{ Slope steepness } & \\
\cline { 2 - 4 } Stream proximity & Steepest (0\% to 20\%) & Moderate (20\% to 60\%) & Low/flat (60\% to 100\%) \\
\hline Closest (0\% to 20\%) & A (Critical) & B (Very high) & C (High) \\
Intermediate (20\% to 60\%) & B (Very high) & C (High) & \\
Furthest (60\% to 100\%) & C (High) & & \\
\hline
\end{tabular}

ity. Relatively deep ditches (i.e., $>2$ $\mathrm{m}[6 \mathrm{ft}]$ ) can provide this topographic relief, and ditch depth can be estimated from a LiDAR-based DEM (using localized "range in elevation" statistics). Local knowledge would be required to identify possible bioreactor sites near tile mains.

Step 7 highlights footslope positions below fields in naturally drained landscapes where soil saturation after rainfall generates surface runoff. Landscape classification (Pennock et al. 1987) and secondary terrain attributes (topographic wetness index) can be used to map convergent footslopes where generation of surface runoff is likely. Producers may be willing to install perennial cover in these wet areas that often challenge timely farming operations. It would be most important to address these runoff sources in relatively steep agricultural watersheds; the gradual relief of Lime Creek watershed does not provide clear examples for illustration.

Step 8 highlights where small impoundments below fields can detain/store water in various landscapes to provide a range of conservation benefits. Nutrient-removal wetlands can enhance nitrate removal from tile drainage on a watershed scale (Tomer et al. 2013), whereas farm ponds and detention basins trap sediment and phosphorus from surface runoff. Wetlands and farm ponds provide additional benefits (e.g., habitat, recreation). Despite differences in the purpose and design of these practices, locations can be proposed using similar approaches based on local terrain and watershed size. Simulated impoundments are evaluated for suitability based on pool area, depth, and volume relative to watershed area. Figure 4e shows possible wetland sites for Lime Creek identified using criteria described by Tomer et al. (2013) but under software control.

Step 9 would propose locations suited for resaturated buffers, which provide for shallow subsurface discharge of tile drainage water along a distribution line placed along the upper boundary of a riparian buffer. This is a new and promising experimental practice that has received attention in the popular press, but initial trials are still ongoing. In general terms, the ideal resaturated buffer site would be found below tile-drained fields, have deep soils with high organic matter contents that can facilitate denitrification, be planted to buffer vegetation, and exhibit a relatively uniform slope across the width of the buffer to minimize risks of bank slumping (where too steep) or saturation of adjacent cropped fields (where too flat). Each of these attributes can be mapped. Criteria might include maximum slopes along the bank, minimum slopes along the buffer's upper margin, and a soil type with a thick (preferably pachic) mollic epipedon.

Step 10 identifies potential locations for two-stage ditches, which provide an alternative to the trapezoidal channel that dominates current ditch design. Installation essentially widens a trapezoidal ditch to construct a vegetated bench to complement a naturally established meander to the normal-flow channel (USDA NRCS 2007). Proponents suggest the two-stage design should be self-maintaining in terms of sediment storage and transport. The vegetated bench provides an environment for enhanced biodiversity, nutrient uptake, and denitrification (Roley et al. 2012). Sites suited to the practice can potentially be mapped based on bank height, which can be mapped using LiDAR. Ditches deeper than about $3 \mathrm{~m}$ (10 ft) would be expensive for two-stage conversion (but could provide bioreactor sites-see Step 6). Figure $4 \mathrm{f}$ highlights where Lime Creek has bank heights $<2.5 \mathrm{~m}(8 \mathrm{ft})$ for possible placement of two-stage ditches.

Step 11 maps features of the riparian corridor to identify key opportunities for 


\section{Figure 5}

(a) Distribution of potential riparian buffer functions in Lime Creek based on table 2 and (b) inset showing runoff pathways, shallow water table areas, and riparian segments used for classification (see Step 11).

(a)

\section{Legend}

\section{Riparian function}
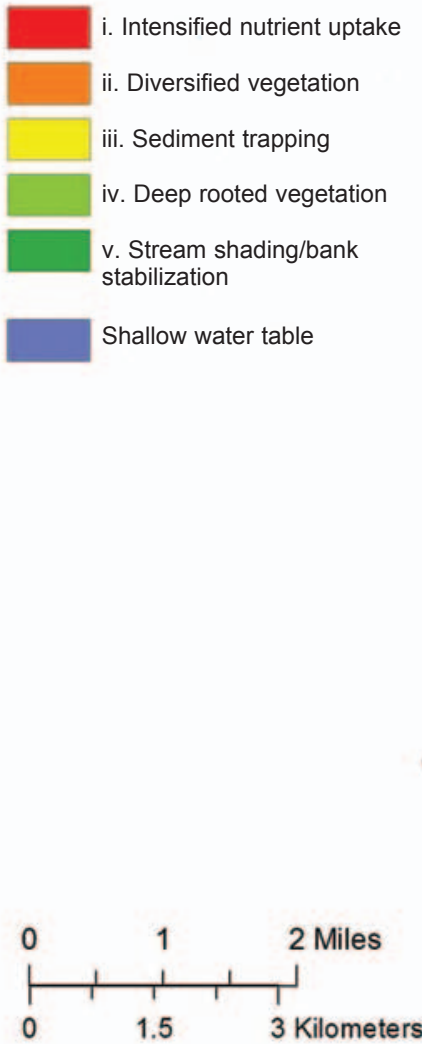

(b)

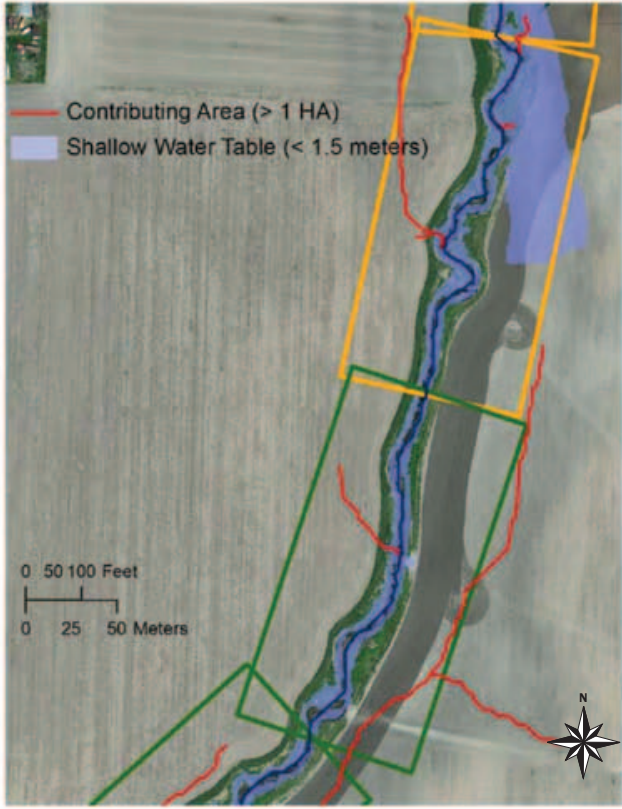

water quality improvement on a reach basis contributing area against the extent of shallow water tables along a riparian zone provides the basis for this mapping concept (figure 5). Many riparian buffers are designed to intercept surface runoff, which is important but not uniformly opportune along streams (Tomer et al. 2003). Where a buffer's vegetation root can interact with a shallow water table, carbon cycling and denitrification may be enhanced (Dosskey et al. 2010). Critical zones for riparian management occur wherever shallow groundwater and surface runoff can be intercepted. Where neither runoff nor groundwater can be intercepted, other benefits such as bank stabilization remain possible. These potential functions can be fulfilled through selection of buffer species and widths (i.e., narrow buffers can stabilize banks, but wide buffers are needed to influence groundwater). Opportunities to trap runoff along riparian corridors can be mapped from a DEM (Tomer et al. 2003). Areas anticipated to have shallow water tables can be mapped by comparing riparian-zone and channel elevations. Figure 5 illustrates the range of riparian

\section{Table 2}

Classification scheme to assess potential riparian functions along Lime Creek (see figure 5).

\begin{tabular}{llll}
\hline & \multicolumn{4}{l}{ Width of riparian zone with shallow water table } \\
\cline { 2 - 5 } Runoff contributions & Widest (0\% to 20\%) & Intermediate (20\% to 60\%) & Least (60\% to 100\%) \\
\hline Closest (0\% to 20\%) & i & ii & iii \\
Intermediate (20\% to $60 \%)$ & ii & ii & ii \\
Least (60\% to 100\%) & iv & iv & V \\
\hline
\end{tabular}


Step 12 identifies opportunities to implement river restoration practices. River restoration is an emerging science, with pool riffle structures, remeandering, oxbow rehabilitation, and floodplainconnecting diversions among the options. Both LiDAR maps and expertise in fluvial systems will be needed to identify specific alternatives. Comprehensive approaches are needed and social constraints must be considered (Wohl et al. 2005). Most river restoration opportunities are located downstream from headwater basins such as Lime Creek.

One Scenario from Compiled Results. The mapped distributions of possible locations for a variety of conservation practices, based on precision geographic information system (GIS) technologies, offer a variety of alternatives for watershed management. Prioritization among and selection from these alternatives depends on many factors, but integrating these precision techniques can help indicate appropriate alternatives, given local priorities and preferences and water quality goals. This step-wise process simply provides a planning resource for local use. In figure 6, we provide one possible scenario for Lime Creek that assumes local preference for wetlands, controlled drainage, grassed waterways, and management of shallow water tables. The result provides a starting point for actual planning; this scenario (figure 6) takes little land out of production and distributes practices to enable most landowners in the watershed to contribute to water quality improvement in a meaningful way.

\section{CONCLUSION}

The suggested planning process is adaptive and can be updated to propose locations for new or innovative practices. We have developed mapping algorithms for those practices illustrated using figures and are developing computer code for several others briefly described. We have proposed this concept with minimal detail on individual practices because opportunities to develop and optimize this framework will become most apparent from trial and application in a variety of settings. This framework concept may be best explored and developed in a crowdsourcing context, but we are working to develop a

\section{Figure 6}

One possible conservation planning scenario for Lime Creek.

\section{Legend}

Controlled drainage potential

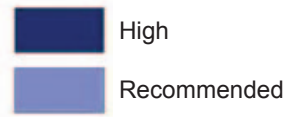

\section{Runoff risk}
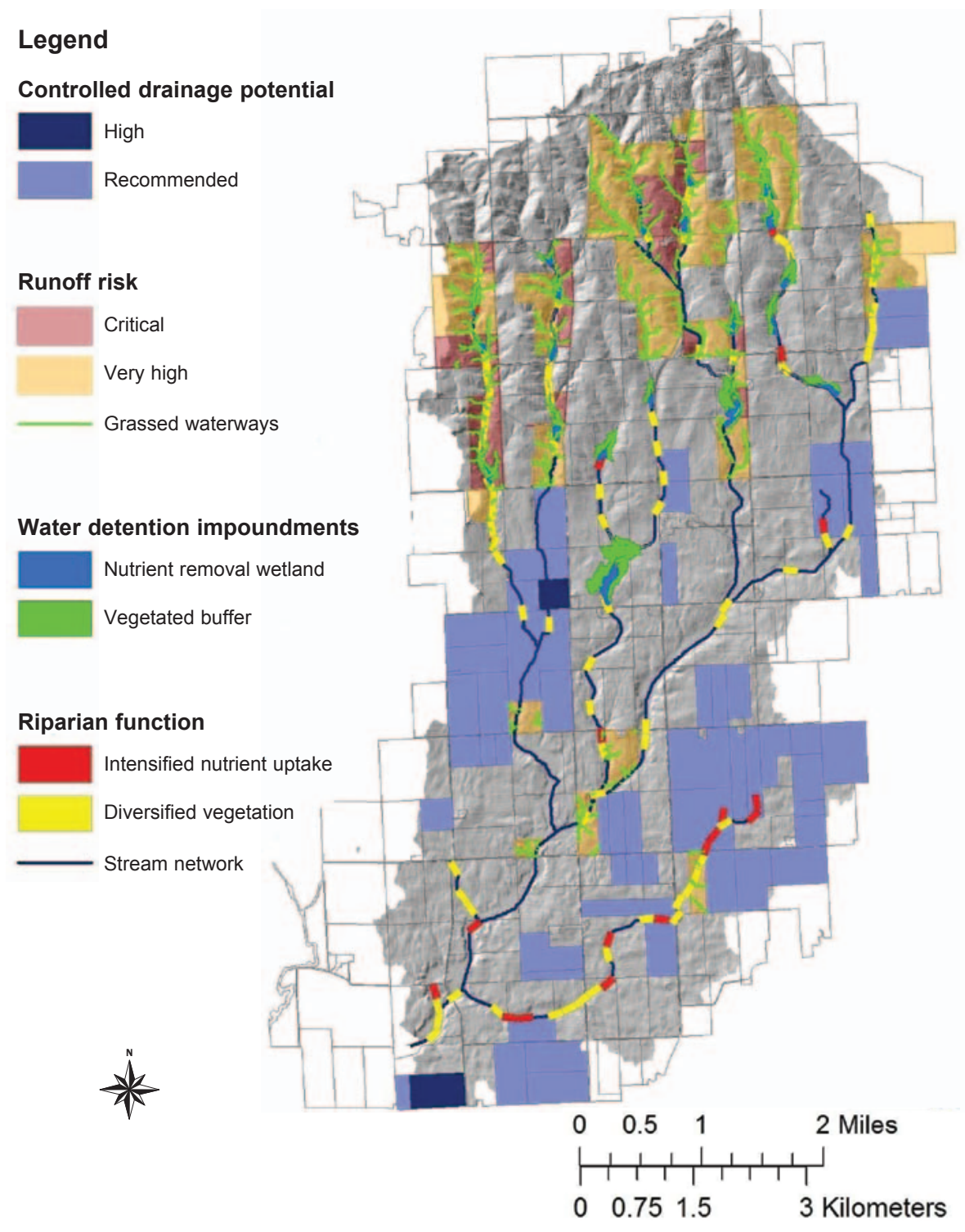

coded software product compatible with ArcGIS software to develop it further. Full application of this concept may depend on how confidently conservation planning scenarios can be compared using watershed simulation models. That would help watershed planners and stakeholders make selections among scenarios meeting local preferences. When considered in a comprehensive framework, precision conservation technologies might help local communities through discussions of landscape visioning, conservation incentives, and shared sacrifice towards both localand national-scale water quality benefits.

\section{REFERENCES}

Arbuckle, J.G. 2012. Farmer attitudes toward proactive targeting of agricultural conservation programs. Society and Natural Resources. DOI :10.1080/08941920.2012.671450.

Delgado, J.A., and J.K. Berry. 2008. Advances in precision conservation. Advances in Agronomy 98:1-44.

Dosskey, M.G., P. Vidon, N.P. Gurwick, C.J. Allen, T.P. Duval, and R. Lowrance. 2010. The role of riparian vegetation in protecting and improving chemical quality in streams. Journal of the American Water Resources Association 46(2):261-277.

FSA (Farm Service Agency). 2012. Imagery programs: NAIP imagery. Washington, DC: USDA 
Farm Service Agency http://www.fsa.usda.gov/ FSA/apfoapp area $=$ home\&subject $=$ prog\&topic $=$ nai.

Iowa Nutrient Reduction Strategy Science Team. 2012. Iowa science assessment of nonpoint source practices to reduce nitrogen and phosphorus transport in the Mississippi River basin. Ames, IA: Iowa State University College of Agriculture and Life Sciences. http://www.nutrientstrategy. iastate.edu/documents.

Joose, P.J., and D.B. Baker. 2010. Context for re-evaluating agricultural source phosphorus loadings to the Great Lakes. Canadian Journal of Soil Science 91:317-327.

Kalita. P.K., A.S. Algoazany, J.K. Mitchell, R.A.C. Cooke, and M.C. Hirschi. 2006. Subsurface water quality from a flat tile-drained watershed in Illinois, USA. Agriculture, Ecosystems, and Environment 115:183-193.

Kibblewhite, M.G., K. Ritz, and M.J. Swift. 2008. Soil health in agricultural systems. Philosophical Transactions of the Royal Society 363:685-701.

Lobell, D.B., K.G. Cassman, and C.B. Field. 2009. Crop yield gaps: Their importance, magnitudes, and causes. Annual Review of Environment and Resources 34(1):179-204.

Montgomery, D.R. 2007. Is agriculture eroding civilization's foundation? GSA Today 17(10):4-9.

Mueller, N.D., G.S. Gerber, M. Johnston, D.K. Ray, N. Ramankutty, and J.A. Foley. 2012. Closing yield gaps through nutrient and water management. Nature 490:254-257.

Paerl, H.W. 2009. Controlling eutrophication along the freshwater-marine continuum: Dual nutrient $(\mathrm{N}$ and $\mathrm{P})$ reductions are essential. Estuaries and Coasts 32(4):593-601.

Pennock, D.J., B.J. Zebarth, and E. DeJong. 1987. Landform classification and soil distribution in hummocky terrain, Saskatchewan, Canada. Geoderma 40(3):297-315.

Pike, A.C., T.G. Mueller, A. Schorgendorfer, S.A. Shearer, and A.D. Karathanasis. 2009. Erosion index derived from terrain attributes using logistic regression and neural networks. Agronomy Journal 101(5):1068-1079.

Roley, S.S., J.L. Tank, M.L Stephen, L.T. Johnson, J.J. Beaulieu, and J.D. Witter. 2012. Floodplain restoration enhances denitrification and reachscale nitrogen removal in an agricultural stream. Ecological Applications 22(1):281-297.

Russell, M.J., D.E. Weller, T.E. Jordan, K.J. Sigwart, and K.J. Sullivan. 2008. Net anthropogenic phosphorus inputs: Spatial and temporal variability in the Chesapeake Bay region. Biogeochemistry 88(3):285-304.

Schipper, L.A., W.D. Robertson, A.J. Gold, D.B. Jaynes, and S.C. Cameron. 2010. Denitrifying bioreactors - An approach for reducing nitrate loads to receiving waters. Ecological Engineering. 36(11):1532-1543.

Smith, D.R., S.J. Livingston, B.W. Zuercher, M. Larose, G.C. Heathman, and C. Huang. 2008. Nutrient losses from row crop agriculture in Indiana. Journal of Soil and Water Conservation 63(6):396-409.

Soil Survey Staff. 2004. Soil Survey for Bureau County, Illinois. USDA Natural Resources Conservation Service. http://soildatamart.nrcs. usda.gov.

Tomer, M.D., W.G. Crumpton, R.L. Bingner, J.A. Kostel, and D.E. James. 2013. Estimating nitrate load reductions from placing constructed wetlands in a HUC-12 watershed using LiDAR data. Ecological Engineering 56:69-78.

Tomer, M.D., D.E. James, and T.M. Isenhart. 2003. Optimizing the placement of riparian practices in a watershed using terrain analysis. Journal of Soil and Water Conservation 58(4):198-206.

Turner, R.E., N.N. Rabalais, and D. Justic. 2008. Gulf of Mexico hypoxia: Alternate states and a legacy. Environmental Science and Technology 42(7):2323-2327.

USDA NASS (National Agricultural Statistics Service). 2012. Cropscape - Cropland Data Layer.
Washington, DC: USDA National Agricultural Statistics Service. http://nassgeodata.gmu.edu/ CropScape/.

USDA NRCS (USDA Natural Resources Conservation Service). 2007. Two-stage channel design. Chapter 10. In National Engineering Handbook, Part 654: Stream Restoration Design. Washington, DC: USDA Natural Resources Conservation Service.

Wilson, J.P., and J.C. Gallant. 2000. Terrain analysis: Principles and applications. New York: John Wiley \& Sons, Inc.

Wohl, E., P.L Angermeier, B. Bledsoe, G.M. Kondolf, L. MacDonnell, D.M. Merritt, M.A. Palmer, N.L. Poff, and D. Tarboton. 2005. River restoration. Water Resources Research. 41:W10301.

Woli, K.P., M.B. David, R.A. Cooke, G.F. McIsaac, and C.A. Mitchell. 2010. Nitrogen balance in and export from agricultural fields associated with controlled drainage systems and denitrifying bioreactors. Ecological Engineering 36(11):1558-1566.

Yaalon, D.H. 2007. Human-induced ecosystem and landscape processes always involve soil change. BioScience 57(11):918-919. 